\title{
JEAN PIAGET E O ENSINO DA GEOGRAFIA ESCOLAR: Um Olhar Sobre o Mapa
}

\author{
Leonardo Pinto dos Santos ${ }^{1}$ \\ Eduardo Schiavone Cardoso
}

\begin{abstract}
RESUMO
Esse artigo é parte de uma pesquisa de Doutorado desenvolvida no Programa de Pós-Graduação em Geografia da Universidade Federal de Santa Maria (UFSM) e que se desenha como uma aproximação do ensino da Geografia com a Epistemologia Genética de Jean Piaget. Para isto trabalhamos com um grupo de adolescentes de uma escola pública do Rio Grande do Sul, localizada no município de Canoas, região metropolitana de Porto Alegre. O grupo é formado por estudantes do 8o ano do Ensino Fundamental em que se buscou trabalhar a reversibilidade e a descentração do pensamento a partir do uso do mapa como ferramenta para se compreender as potencialidades de pensamento destes sujeitos.
\end{abstract}

Palavras-chave: Geografia. Ensino de Geografia. Jean Piaget. Epistemologia genética.

\section{JEAN PIAGET AND THE TEACHING OF SCHOOL GEOGRAPHY: A LOOK AT THE MAP}

\begin{abstract}
This article is part of a doctoral research developed in the Postgraduate Program in Geography of the Federal University of Santa Maria (UFSM) and is designed as an approximation of the teaching of Geography with the Genetic Epistemology of Jean Piaget. For this, we worked with a group of adolescent from a public school in Rio Grande do Sul, located in the municipality of Canoas, metropolitan region of Porto Alegre. The group is formed by students of the 8th year of elementary school in which it was sought to work the reversibility and decentration of thought from the use of the map as a tool to understand the potentialities of thinking of these subjects.
\end{abstract}

Keywords: Geography. Geography teaching. Jean Piaget. Genetic epistemology.

Recebido em: 10/7/2019

Aceito em: 8/9/2019

\footnotetext{
1 Técnico em Geoprocessamento pelo Colégio Politécnico (2013). Graduado em Geografia Licenciatura Plena pela Universidade Federal de Santa Maria (2013). Especialização em Mídias na Educação (2018) e mestre em Geografia pela Universidade Federal do Rio Grande do Sul (2015). Doutor em Geografia pela Universidade Federal de Santa Maria (2019). Professor-adjunto da Faculdade de Geografia da Universidade Federal do Pará - Campus Altamira. Tem experiência na área de Geografia, atuando principalmente nos seguintes temas: Educação Geográfica, Ensino-Aprendizagem, Livro Didático, Epistemologia Genética, Espaço Mentalmente Projetado, Autonarrativas e Formação Docente. http://lattes.cnpq.br/3529012895113506. https://orcid.org/0000-0003-2997-1081. leonardoufsm@hotmail.com

2 Graduação em Geografia Licenciatura (1991) e em Geografia - Bacharelado (1998) - pela Universidade de São Paulo. Mestrado em Geografia - Geografia Humana - (1996) e Doutorado em Geografia - Geografia Física - (2001) pela Universidade de São Paulo. Pós-Doutorado pela Universidade Estadual Paulista Júlio de Mesquita Filho (2010). Professor titular da Universidade Federal de Santa Maria. Tem experiência na área de Geografia, com ênfase em Geografia Humana, atuando principalmente nos seguintes temas: Pesca Artesanal, Pescadores, Natureza, Território. http://lattes.cnpq.br/6467146489705005. https://orcid.org/0000-0002-9240-578X. educard2016@gmail.com
} 
Este artigo é parte de uma tese de Doutorado defendida na Universidade Federal de Santa Maria (UFSM) que visa a entender como um aluno constrói suas representações em relação a espaços que ele não vivencia. Para essa tarefa buscamos na Epistemologia Genética (PIAGET, 2012) as ferramentas conceituais para este entendimento, centrando a atenção nas ações que o sujeito aluno realiza ao interagir com materiais que são utilizados comumente em aulas de Geografia na Educação Básica.

Destacamos uma destas práticas em que os alunos manusearam um planisfério com a finalidade de organizar os continentes e oceanos a partir de um ponto de referência predeterminado. O objetivo foi trabalhar com a capacidade do pensamento reversível dos alunos, tentando observar se estes sujeitos conseguem descentrar do seu egocentrismo para solucionar o desafio proposto.

Utilizamos, para isso, dois conceitos importantes no corpo teórico piagetiano: descentração e reversibilidade. Basicamente, estes dois conceitos explicam de que forma uma pessoa consegue perceber e entender outros pontos de vista em relação a uma questão que se está analisando, passando a se considerar um leque maior de possibilidades em relação a determinado ponto.

Sobre a descentração, Piaget (1990, p. 76) afirma que é "o deslocar o próprio centro de interesse e o comparar uma ação com outras ações possíveis, em particular as ações dos outros".

Uma espécie de revolução copernicana que consiste em descentrar as ações em relação ao próprio corpo, em considerá-lo um objeto entre outros num espaço que os contém a todos, e em ligar as ações dos objetos sob o efeito das coordenações de um sujeito que começa a conhecer-se enquanto fonte ou mesmo enquanto senhor de seus movimentos (PIAGET, 2012, p. 11).

Já Inhelder e Piaget (1976, p. 205) trabalham a questão da reversibilidade. Dentro da teoria piagetiana é possível entrelaçar a reversibilidade com a inteligência humana, em que uma pessoa seria considerada "inteligente" quanto maior fosse sua possibilidade de reversibilidade ao se analisar a realidade, ou seja, quanto melhor fosse sua capacidade de efetuar operações mentais sobre determinado objeto.

A reversibilidade, que é a possibilidade permanente de uma volta ao ponto de partida, se apresenta sob duas formas distintas e complementares. Podemos voltar ao ponto de partida anulando a operação efetuada, o que constitui uma inversão ou negação: o produto da operação direta e de seu inverso é, então, a operação nula ou idêntica. Mas podemos também voltar ao ponto de partida anulando uma diferença (no sentido lógico do termo), o que constitui uma reciprocidade: o produto de duas operações recíprocas é, então, não uma operação nula, mas uma equivalência.

Desta forma, a finalidade foi selecionar itens que pudessem testar o grau de reversibilidade do pensamento de estudantes, ajuizando de que maneira eles conseguem resolver problemas com um nível de abstração que emprega o uso de diferentes relações espaciais constituídas para se tornarem inteligíveis. No caso, foi disponibilizado para uma turma de 8ㅇ ano de uma escola pública do município de Canoas-RS um tipo de planisfério para que eles trabalhassem sua organização tomando a América do Sul em uma referência diferente do que habitualmente se observa nos produtos cartográficos presentes em grande parte dos ambientes escolares. 


\section{UM POUCO SOBRE JEAN PIAGET}

Jean Piaget (1896-1980) produziu uma grande variedade de artigos e livros em seus quase 70 anos de trabalho, remodelando a compreensão que o campo científico tinha da criança e do adolescente, principalmente no que tange ao desenvolvimento da inteligência e, por consequência, como ocorre a construção do conhecimento.

Quase 40 anos após sua morte, seus trabalhos continuam a influenciar uma grande gama de pesquisas dentro e fora do campo educacional, ponto este tangente dentro da sua vasta produção, tanto que se existem, basicamente, dois livros abordando diretamente a educação: Para onde vai a educação? (1978), que é redigido em 1971 a pedido da Unesco, e Psicologia e Pedagogia (2015), que é um volume composto por dois textos (um de 1935 e outro de 1965) em que Jean Piaget escreve para o Tomo XV da Enciclopédia Francesa.

Ele começou sua produção intelectual muito cedo (antes mesmo de completar 18 anos), publicando seus primeiros artigos ainda na sua juventude em Neuchâtel. "Segundo Jean-Jacques Ducret, o seu primeiro verdadeiro artigo de zoologia data de 1911 (Les limnées des lacs de Neuchâtel, Bienne, Morat et des environs)" (BARRELET; PERRET-CLERMONT [19--], p. 73), destacando-se que há publicações anteriores já "aos dez ou onze anos, observando um pardal parcialmente albino em um parque, publicou um artigo de uma página em um periódico de história natural de Neuchâtel" (MACEDO, 1994, p. 3). O próprio Piaget $(1976$, p. 7) relata essa sua primeira publicação:

A la edad de diez u once años, inmediatamente después de haber entrado en el "colegio latino", decidí ser más serio. Habiendo tenido oportunidad de observar un gorrión parcialmente albino en un parque público, envié un artículo de una página a un periódico de historia natural de Neuchâtel. Mi artículo fue publicado: İestaba "lanzado"!

Piaget (1976, p. 7) narra, ainda, no início de sua biografia, o curioso caso de suas primeiras publicações em torno da malacologia (ramo da Biologia que estuda os moluscos), em que outros especialistas da área gostariam de conhecê-lo, mas como era muito jovem negava os convites. Quando descobrem sua real identidade (idade) chegam a negar a publicação de um artigo.

Esta iniciación precoz en la malacología tuvo una profunda influencia sobre mí. Cuando en 1911 Godet murió, yo sabía bastante sobre el tema para empezar a publicar sin ayuda (los especialistas son escasos en este dominio) una serie de artículos sobre los moluscos de Suiza, de Saboya, de Bretaña e incluso de Colombia. Esto me valió algunas experiencias divertidas. Algunos de mis "colegas" extranjeros quisieron verme, pero como yo no era nada más que un escolar, no osaba mostrarme y debí declinar esas invitaciones halagadoras.

Tendo uma vida voltada para a pesquisa e com um número elevado de publicações, encontramos dentro da Epistemologia Genética uma variedade de resultados empíricos e teóricos que congregam certa continuidade, o que permitiu que ele, junto com colegas, estruturasse um corpo teórico para entender o desenvolvimento do pensamento dos sujeitos, da infância à idade adulta. Esse quadro teórico-prático encontra ninho dentro do ambiente escolar, potencializando o papel do professor, que pode pen- 
sar suas ações pedagógicas apoiado em um substrato conceitual visando a compreender os caminhos utilizados pelas crianças e adolescentes em suas leituras do Espaço Geográfico.

Neste sentido, a Epistemologia Genética de Jean Piaget e a Geografia escolar se interconectam, pois o pesquisador genebrino criou todo um corpo teórico-prático que permite compreender as instâncias percorridas por um indivíduo na construção do espaço. Esse processo encontra consonância direta com a forma como o aluno lê e compreende o Espaço Geográfico, objeto maior de análise da ciência geográfica.

\section{A PRÁTICA COM MAPAS}

A prática pedagógica aqui apresentada é quase que obrigatória nas aulas de Geografia, pois envolve a pintura de um mapa. Ao mesmo tempo que é ponto comum, ela carrega em seu cerne uma ampla potencialidade quando se fala no pensamento operatório do aluno, sendo de fácil realização, pois precisa de poucos materiais: régua, tesoura, cola, material para colorir, imagem com os contornos dos continentes (Figura 1) e folha de ofício.

\section{Figura 1 - Continentes para Recorte}
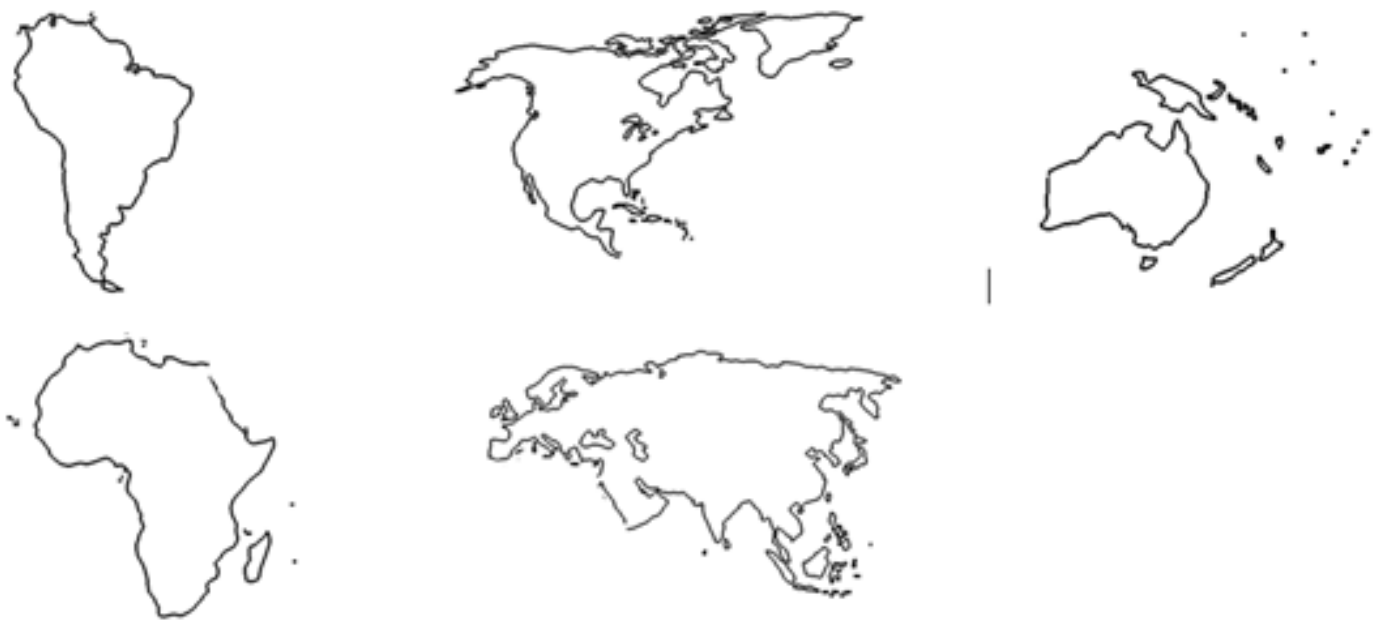

Fonte: Organização dos autores.

Para o desenvolvimento da atividade foi disponibilizado para cada aluno uma cópia da Figura 1, em que há os continentes da América do Sul, África, Oceania (esses três separados); Europa e Ásia; América do Norte e América Central (estes juntos); a Antártica não foi inserida. Nessa ocasião cada aluno foi orientado a pintar os continentes, depois recortá-los e colá-los em uma folha de ofício em que havia a indicação da América do Sul, como mostra a Figura 2 no canto superior esquerdo da folha de ofício. 
Figura 2 - Representação da Indicação de Colagem na Folha

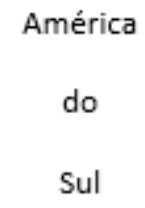

Fonte: Organização dos autores.

Após a colagem da América do Sul, cada aluno precisou conceber a folha como sendo um planisfério e fixar os demais continentes tendo como referência a indicação do professor. Com os continentes organizados, eles inseriram os oceanos Atlântico, Pacífico e Índico na nova organização, e, elaboraram a legenda, dando por fim um título ao mapa. Para realizar com êxito essa ação o sujeito precisa ter transposto as relações espaciais iniciais que compõem a topologia, estando com aspectos do projetivo e do euclidiano estruturados, o que permite coordenar objetos entre si em um sistema de referência móvel.

As relações projetivas não apagam os esquemas estabelecidos anteriormente, mas o enriquecem, liberando ao sujeito uma maior reversibilidade de pensamento, o que abre um novo leque de possibilidades para o ensino da Geografia. Questões como direita-esquerda tornam-se uma ação de fácil resolução por parte do aluno, que pode, em um mesmo momento, considerar os objetos na direita-esquerda uns dos outros. Isso evidencia uma liberação do egocentrismo que impedia a coordenação de pontos de vista.

Assim sendo, essa prática consegue incorporar o uso dos três tipos de relações espaciais estruturadas por Piaget. Das relações topológicas há o envolvimento de noções como junto e separado, de vizinhança e de continuidade; da projetiva existe a coordenação de pontos de vista e de perspectivas; e do euclidiano utiliza a referência fixa e inúmeras conservações que apresentam como base a ideia de distância associada à medida linear, de superfície, entre outras.

Como o sujeito precisa se valer de distintos esquemas estruturados em diferentes fases de seu desenvolvimento, essa atividade tem um alto valor em se compreender um panorama das capacidades cognitivas deste aluno, além de ser ponto de desequilíbrio, pois pode servir de ponte para a construção de esquemas ainda não estruturados.

De forma prática, esse mesmo aluno, ao conseguir resolver o que foi proposto, passa a considerar como válida a afirmação de que Santa Catarina encontra-se ao mesmo tempo "embaixo" do Paraná e "em cima" do Rio Grande do Sul. Percebe que um objeto pode estar tanto à esquerda como à direita, dentro de um conjunto de itens inseridos em um sistema de referência móvel ou fixo. É a partir deste ponto que o aluno pode transferir a orientação corporal para a orientação geográfica, estabelecendo as direções Norte-Sul-Leste-Oeste em um espaço tridimensional ou em uma superfície plana, ou seja, passa a compreender a orientação de um mapa, por exemplo. 
Vale aqui o destaque de que as relações espaciais euclidianas desenvolvem-se concomitantemente às projetivas, aproveitando-se também das bases desenvolvidas durante as noções espaciais fundamentais topológicas, não tendo uma anulação ou destruição do que já se havia construído, mas sim uma soma que vai se tornando mais complexa em benefício da leitura do espaço, algo como o que pode ser visto no esquema da Figura 3.

Figura 3 - O Espaço e as Relações Espaciais

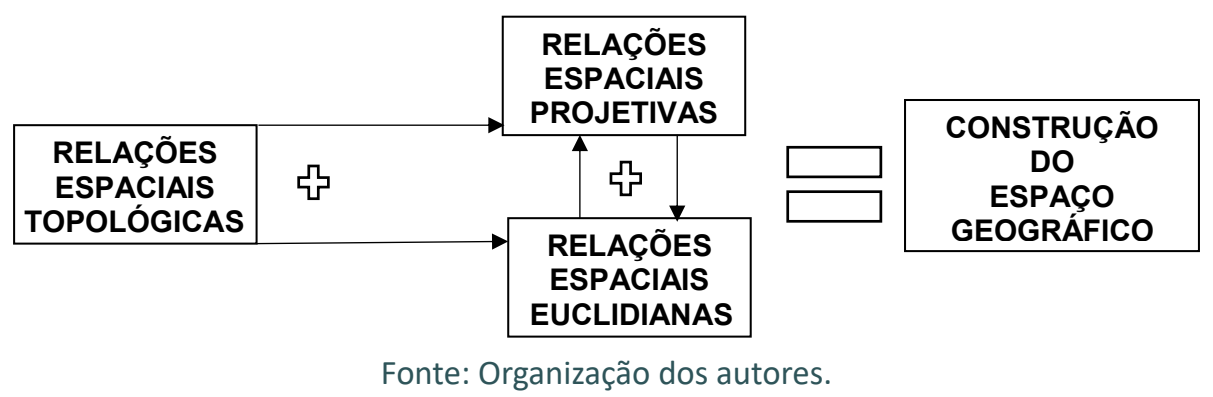

Como Piaget e Inhelder (1993, p. 11-12) destacam no prólogo do livro A Representação do Espaço na Criança, "nós constataremos precisa e incessantemente que o espaço infantil, cuja natureza essencial é ativa e operatória, começa por intuições topológicas elementares, bem antes de tornar-se simultaneamente projetivo e euclidiano". No mesmo caminho, Oliveira (1978, p. 61), assegura que "as primeiras operações espaciais engendradas pela criança são topológicas, e a partir delas é que são estabelecidas simultaneamente as relações projetivas e euclidianas". Dessa forma, as relações espaciais euclidianas chegam para enriquecer ainda mais a leitura espacial do jovem que se inicia no período sensório-motor com as relações topológicas, e vai sendo enriquecida a partir do ponto em que há o desenvolvimento concomitante das relações projetivas e euclidianas nos estágios concreto e formal.

Um exemplo das diferenças entre um sujeito na fase topológica, na projetiva e na fase euclidiana é exposto a seguir: para se localizar considerando a proximidade em relação a alguma coisa, o primeiro dirá que está próximo da estrada $A$; o segundo afirmará que ele está à esquerda da estrada $B$; já um terceiro indivíduo conseguirá localizar o objeto, considerando a distância dele em relação às bordas do desenho ou, então, em relação às duas estradas (PAGANELLI; ANTUNES; SOIHET, 1985). Como o nome já destaca, euclidiana deriva de Euclides de Alexandria, um dos principais matemáticos da Grécia antiga e que ficou conhecido como "pai da Geometria".

Basicamente, as relações euclidianas são relações métricas que o sujeito incorpora em suas análises. Questões como: conservação de distâncias, de comprimentos, de superfícies e construção de eixos de coordenadas conduzem o aluno a situar os objetos uns em relação aos outros, tomando como ponto de partida um sistema de referência fixo.

Isso é destacado por Almeida e Passini (2011, p. 39), ao afirmarem que "a construção das relações espaciais euclidianas implica a conservação de distância, comprimento e superfície e a construção da medida de comprimento". Essas novas conservações permitem ao adolescente situar os objetos uns em relação aos outros, seguindo uma lógica 
necessária para organizar materiais como maquetes e croquis. Nesse nível das relações espaciais, os jovens podem coordenar medidas e utilizar os referenciais de altura e comprimento. Da mesma forma, questões como vertical e horizontal são compreendidas e tornam o sujeito competente para construir um sistema de coordenadas.

A partir destas exposições foi pensada a prática envolvendo o deslocamento de pontos de vista e objetos dentro de um sistema fixo. Ela foi desenvolvida com uma turma de 8o ano, com alunos entre 13 e 17 anos. Nesta fase eles já podem ser euclidianos (na teoria piagetiana, é a partir dos 11-12 anos que o sujeito situa os objetos independentemente de sua própria posição). Para resolver o problema proposto, o aluno deve correlacionar relações espaciais dos três níveis; por exemplo, necessita da vizinhança (topológica), coordenar pontos de vista (projetivo) e conservação de superfície e distância (euclidiana).

O jovem passa a utilizar um sistema de referência, tomando a folha como um planisfério, correlacionando as relações espaciais que vão se agregando ao longo do desenvolvimento para determinar questões como a localização dos continentes e dos oceanos. A proposta de inserir os oceanos Atlântico, Pacífico e Índico torna-se importante, uma vez que o adolescente necessitará realizar um outro movimento mental para localizá-los corretamente dentro de um quadro com referências definidas.

A indicação para a construção de uma legenda também apresenta seus ganhos, pois é possível trabalhar com pontos inerentes a ela, bem como envolver trabalhos com outros componentes curriculares, como a Arte e a Física, fazendo com que, em uma mesma atividade, diferentes esquemas sejam acionados para a resolução do problema proposto, elevando-se os desequilíbrios possíveis.

A partir dela pode-se trabalhar o jogo de cores presentes em um mapa ou mesmo outros tipos de variáveis visuais ou gráficas como forma, tamanho, granulação ou textura. A cada novo desafio proposto ao aluno ele necessita relacionar uma série de esquemas e estruturas para chegar ao objetivo de organizar as informações solicitadas nos locais indicados. Fazendo isso, seu pensamento tende a buscar um equilíbrio visando a tornar o seu pensamento reversível.

O papel do professor nestes momentos é o de observação. Dessa forma, é possível ver os encaminhamentos dados pelos alunos na tentativa de coordenar os objetos dentro de um sistema de referência, ficando evidentes os sujeitos que ainda não estão dominando as relações espaciais projetivas e, principalmente, as euclidianas. Pode, assim, verificar até mesmo as defasagens em relação às relações espaciais topológicas. Frases como: "professor, isso é impossível!", "professor, posso colar uma folha na outra?, "como vou colocar todos os continentes em uma folha deste tamanho?", "professor, a América do Sul não deveria estar aqui?" (indicando o canto inferior esquerdo), "professor, as Américas Central e do Norte não deveriam estar aqui, como vou fazer isso?" (referindo-se à folha em que a indicação de colagem da América do Sul encontra-se na parte superior esquerda, a aluna apontou a colagem acima dela, portanto fora da folha), "professor, que continente é esse?" 
Frases deste tipo demonstram falta de coordenação entre os pontos de vista possíveis, dificuldade de conservação de distâncias e de organização com pontos de referências fixos. Também apresentam deficiências em conceitos como a questão da escala, além da cristalização de uma visão eurocêntrica de mundo, que considera a Europa na parte superior e central do mapa. Essas respostas por parte dos alunos comprovam:

a. Que nem todos os sujeitos chegam ao estágio esperado, levando em conta somente a faixa etária, o que corrobora com o pressuposto piagetiano de que o inatismo em si não pode explicar o desenvolvimento cognitivo do ser humano.

b. Que uma educação tradicional, em que alunos são pouco desafiados em questões de coordenação de pontos de vista e reversibilidade do pensamento, tem como consequência um atraso no desenvolvimento do sujeito. Isso evidencia que o meio (aqui englobando aspectos como a classe social, a escola, a família e amigos, a cultura, o ambiente de maneira geral) não favorece a interação. Assim sendo, trocas simbólicas e concretas realizadas na vida social evitam ou mantêm tardia a construção de estruturas operatórias.

c. Serem verdadeiras as palavras de Becker (2012, p. 124): "o professor precisa 'aprender' seu aluno" (no sentido de compreender suas capacidades de pensamento deste estudante), para que a partir deste ponto possa falar de um Espaço Geográfico que é passível de ser compreendido pelo sujeito, haja vista que ele já tem as estruturas formadas. De outro modo, conforme Becker (2011, p. 85), referindo-se ao professor, este:

Impõe ao aluno o aprendizado de conteúdos/comportamentos de que ele não necessita, pelo qual não se interessa, pois não faz parte de seu universo (motivação cultural), e para o qual, frequentemente, não está preparado (motivação estrutural).

d. Que entre os modelos epistemológicos e teorias de aprendizagem, o empirismo e o apriorismo não tornam o aluno capaz de entender o Espaço Geográfico que se constrói de forma relacional, revelando-se para isso a melhor opção a teoria de cunho interacionista. Nessa perspectiva, explica-se o processo de aprendizagem por uma síntese integradora entre o sujeito e o mundo, síntese esta realizada por ele próprio a partir de suas experiências físicas e lógico-matemáticas.

d. Por fim, que a atividade de pintura de mapas pode e deve ser realizada em sala de aula, como forma de trabalhar conhecimentos básicos como identificação de lugares, relações de vizinhança e distância. Ela em si, contudo, não pode se resumir a uma simples pintura e indicação de determinadas informações, pois carrega em si um potencial para desenvolver o pensamento operatório do aluno, um aspecto de destaque para a compreensão do Espaço Geográfico.

Uma variante desta atividade pode ser encontrada em dois trabalhos: Costella (2008) e Costella e Santos (2013), em que no lugar do deslocamento da América do Sul aqui empregada foi solicitada a mudança de orientação da Índia, demonstrando as possibilidades que este tipo de prática apresenta para o ensino da Geografia escolar. 
A atividade proposta na oficina referida compreende representar a Índia no centro do mapa, localizando todos os continentes e oceanos em relação a ela. Para que essa atividade seja realizada, é necessário que os alunos tenham desenvolvido a reversibilidade espacial, apresentando a noção da localização dos espaços sob diferentes pontos de vista. Ao realizar o trabalho desafiador, os alunos precisam refletir sobre diferentes aspectos: primeiro, imaginar o mundo numa determinada ordem espacial e, depois, reverter essa ordem, retirando o continente africano do centro do mapa, situação tradicional, e colocando em seu lugar a Índia. Ao movimentar espacialmente a Índia, os oceanos e continentes também são movimentados, necessitando para isso situar um país em relação a um sistema de referência que são outros continentes, e até mesmo a um sistema de coordenadas que se localizem no espaço. É como se rodasse paralelamente um mapa, deslocando, numa determinada ordem natural, os continentes e os oceanos (COSTELLA; SANTOS, 2013, p. 85).

A possibilidade de os sujeitos encontrarem uma organização plausível dentro de um sistema de referência fixo é o melhor exemplo de como o pensamento dele se torna reversível, pois, para essa organização é desprendido um conjunto de esquemas estruturados ao longo de um demorado período de desenvolvimento. Em uma atividade deste tipo tornam-se mais claras as dificuldades que os estudantes enfrentam quando deparados com um produto cartográfico.

Dentro das categorias da Geografia, essa prática aproxima-se do Espaço Geográfico, pois utiliza um conjunto de esquemas superiores que permitem ao sujeito diferenciar e orientar espacialmente os objetos dentro de um sistema de referência. Estes esquemas usados para resolver o problema apresentado são os mesmos que o indivíduo irá utilizar para refletir sobre a realidade de forma a questionar e relacionar o que se encontra posto.

\section{CONCLUSÕES}

Nesta prática obtivemos 26 produções dos alunos, em que se tornou possível afirmar que é uma atividade que necessita de um conjunto de estruturas do pensamento formal para ser resolvida. Ao desenvolvê-la, o sujeito precisa pensar de forma reversível para espacializar corretamente as informações solicitadas.

Como consequência, os estudantes tiveram dificuldade para resolver, pois seguindo os pressupostos dos estágios piagetianos, estes jovens ainda estão no caminho de desenvolvimento destas estruturas do pensamento, o que resultou que dez alunos $(38,46 \%)$ (Figura 4$)$ conseguissem ter êxito no que havia sido proposto. 


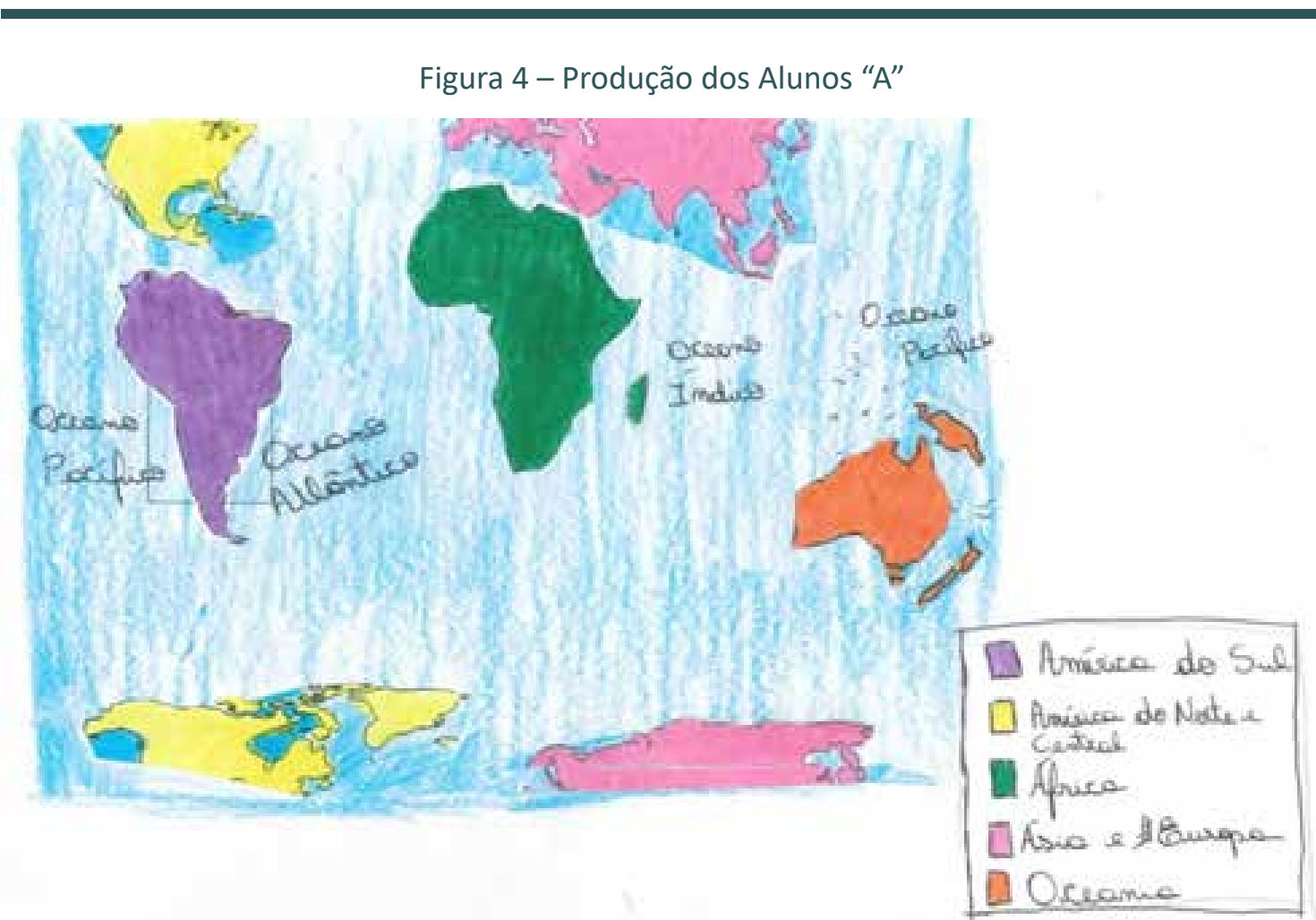

Fonte: Organização dos autores.

Este é um resultado que até certo ponto nos surpreendeu, se for pensado que este grupo ainda está inserido em um patamar de desenvolvimento de estruturas que configuram o pensamento formal. Na outra ponta do processo de pensamento, tivemos apenas dois alunos $(7,69 \%)$ perguntando se podiam colar mais uma folha, pois era impossível espalhar os continentes em uma única folha de ofício. Ao questioná-los como é que se faz para colocar todos os continentes com uma gama de informações em um mapa que eles normalmente observam, não houve resposta, somente ficaram pensativos e procuraram resolver o problema proposto.

Outros nove alunos (34,61\%), (Figura 5) acabaram reproduzindo a visão de planisfério que normalmente é visto, não levando em conta a questão espacial de distribuição, nem mesmo o espaço disponível na folha que serviu como base. Ao colocar a indicação da América do Sul na parte superior da margem esquerda da folha, não foi respeitado o espaço disponível e "compactaram" a América do Norte, América Central e a Europa/Ásia para que entrassem "à força" e o mapa apresentado ficasse próximo ao habitual. 


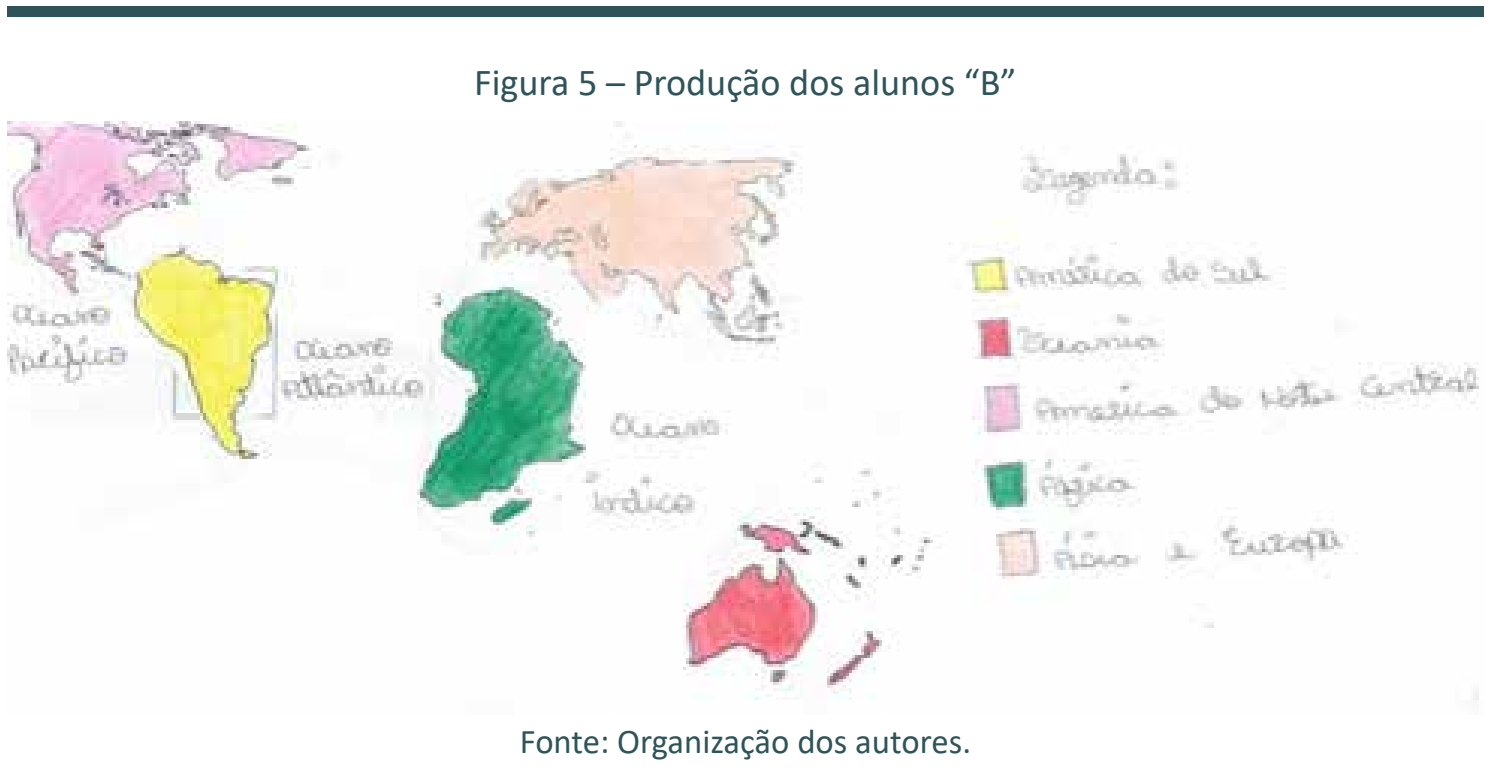

Este tipo de resposta mostra que estes sujeitos ainda não estão prontos a responder questões para as quais teriam condições se suas interações para com o meio tivessem sido de maior profundidade. $O$ grupo de operações referentes à espacialidade, por exemplo, que neste nível se espera que já tivessem desenvolvido, ainda não estão completas, visto que há uma lacuna em seu desenvolvimento que necessita ser trabalhada, para que este consiga pensar o espaço com maior aptidão.

Ao serem levados a um outro ponto de vista, fica visível que alguns esquemas ainda não estão desenvolvidos a fim de solucionar o que foi indicado, colocando-os com certo atraso diante das indicações de Piaget $(2012,2015)$, mas nada fora de um padrão aceitável. Apenas faz pensar que é preciso, enquanto professores, buscar diferentes possibilidades para que os alunos atinjam o patamar de equilíbrio necessário, permitindo-Ihes reunir, em um mesmo todo, o grupo de operações proposicionais que os levem a um pensamento hipotético-dedutivo.

Uma aluna $(3,85 \%)$ não respeitou a indicação de colagem da América do Sul no local indicado e somente reproduziu o mapa como se nada houvesse mudado, o que impediu uma análise. Outros cinco alunos (19,23\%) espacializaram corretamente a América do Sul, a África e a Oceania, mas os outros continentes apenas foram colocados logo abaixo dos localizados na parte superior, sem levar em conta as fronteiras existentes entre a América Central e América do Sul e a divisão do Mar Mediterrâneo entre o norte da África e a parte sul da Europa, por exemplo.

Existiu um caso em que a aluna (3,85\%) errou a espacialidade dos continentes e localização dos oceanos, mas este resultado precisa ser visto com outro olhar, pois ela apresenta dificuldades cognitivas atestadas a partir de laudo médico. É importante destacar essa situação pensando dentro da teoria piagetiana, visto que não há indícios que ela não poderá atingir o pensamento hipotético-dedutivo, mas certamente apresenta um outro tempo de desenvolvimento que é diferente do de seus colegas. É possível que ainda o seu organismo seja capaz de construir as estruturas necessárias para solucionar uma questão, como a correlação correta de continentes em um planisfério. 
Ao refletirmos sobre o modo de aplicação desta prática, é evidente que existem diferentes formas de se desenvolver uma atividade com um grupo de alunos, por exemplo, se o professor apresentar conotação empirista ou inatista. Ele pode repetir a atividade de diversas formas até que seus alunos consigam acertar o que se pede, ou ainda deixar a mesma prática para mais tarde, acreditando que aquele organismo ainda não está pronto para responder àquilo que se solicitou.

Há também a forma construtivista, que propõe um problema a ser respondido e abre espaço para que o sujeito desenvolva uma ação, que pode ou não levar a uma resposta correta. O mais importante, porém, não é o acerto da atividade por parte do aluno, e sim esse movimento de coordenação de ação e as operações que o pensamento vai realizar, tentando encontrar uma solução.

Mesmo que este indivíduo não chegue à resposta esperada, ele vai estar agindo, e neste ir e vir, vai, de diferentes formas, buscar um estado de equilíbrio momentâneo, o que leva à constituição de diferentes esquemas que o ajudarão a enfrentar outras realidades que se apresentem em sua idade escolar ou mesmo fora deste espectro espaçotemporal.

Neste sentido, é possível afirmar que o corpo teórico piagetiano pode ajudar o professor a entender as dificuldades e facilidades que os alunos apresentam ao resolverem um problema, fazendo com que nós docentes possamos pensar em práticas que eles possam resolver, ou mesmo que os desafiem a refletir sobre o Espaço Geográfico.

\section{REFERÊNCIAS}

ALMEIDA, Rosângela Doin de; PASSINI, Elza Yasuko. O espaço geográfico: ensino e representação. 15. ed. 5. reimp. São Paulo: Contexto, 2011.

BARRELET, Jean-Marc; PERRET-CLERMONT, Anne-Nelly. Jean Piaget aprendiz e mestre. Tradução Fernanda Oliveira. Lisboa: Instituto Piaget, [19--].

BECKER, Fernando. O caminho da aprendizagem em Jean Piaget e Paulo Freire: da ação à operação. 2. ed. Petrópolis: Vozes, 2011.

BECKER, Fernando. Ensino e pesquisa: qual a relação? In: BECKER, Fernando; MARQUES, Tania Beatriz Iwaszko (org.). Ser professor é ser pesquisador. 3. ed. Porto Alegre: Mediação, 2012. p. 11-20.

COSTELLA, Roselane Zordan. O significado da construção do conhecimento geográfico gerado por vivências e por representações espaciais. 2008. 202f. Tese (Doutorado em Geografia) - Universidade Federal do Rio Grande do Sul, Porto Alegre, 2008.

COSTELLA, Roselane Zordan; SANTOS, Leonardo Pinto dos. A construção do conhecimento em Jean Piaget e os mapas mentais: a leitura de alunos em diferentes realidades. In: Revista FSA, v. 10, n. 3, p. 80-96, jul./set. 2013. Disponível em: http://www4.fsanet.com.br/revista/index.php/fsa/article/view/240. Acesso em: 11 maio 2018.

INHELDER, Bärbel; PIAGET, Jean. Da lógica da criança à lógica do adolescente: ensaio sobre a construção das estruturas operatórias formais. Tradução Dante Moreira Leite. São Paulo: Pioneira, 1976.

MACEDO, Lino de. Ensaios construtivistas. 2. ed. São Paulo: Casa do Psicólogo, 1994.

OLIVEIRA, Lívia de. Estudo metodológico e cognitivo do mapa. 1978. 128f. Tese (Livre Docência) - Universidade Estadual Paulista Campus de Rio Claro, São Paulo, 1978.

PAGANELLI, Tomoko Iyda; ANTUNES, Aracy do Rego; SOIHET, Rache. A noção de espaço e de tempo: o mapa e o gráfico. In: Revista Orientação, São Paulo: Instituto de Geografia, USP, n. 6, 1985.

PIAGET, Jean. Autobiografía: el nacimiento de la inteligencia. Buenos Aires: Ediciones Caldén, 1976.

PIAGET, Jean. Para onde vai a educação? Tradução de Ivette Braga. 6. ed. Rio de Janeiro: Livraria José Olympio Editora, 1978. 


\section{\& Contexto}

PIAGET, Jean. Comentários de Piaget sobre as observações críticas de Vygotsky concernentes a duas obras: Linguagem e o Pensamento da Criança e o Raciocínio da Criança. Em Aberto, Brasília, ano 9, n. 48, p. 69-77, out./dez. 1990. Disponível em: http://emaberto.inep.gov.br/index.php/emaberto/article/viewFile/749/671. Acesso em: 24 fev. 2018.

PIAGET, Jean. Epistemologia genética. Tradução Álvaro Cabral. 4. ed. São Paulo: Editora WMF Martins Fontes, 2012.

PIAGET, Jean. Psicologia e pedagogia. Tradução Dirceu Accioly Lindoso e Rosa Maria Ribeiro da Silva. 10. ed. Rio de Janeiro: Forense Universitária, 2015.

PIAGET, Jean; INHELDER, Bärbel. A representação do espaço na criança. Tradução Bernardina Machado de Albuquerque. Porto Alegre: Artes Médicas, 1993. 